\title{
Urological referral of asymptomatic men in general practice in England
}

\author{
J Melia*,', P Coulson', D Coleman' and S Moss' \\ 'Cancer Screening Evaluation Unit, Section of Epidemiology, Institute of Cancer Research, Sir Richard Doll Building, Cotswold Road, Sutton, Surrey SM2 \\ $5 N G, U K$
}

The Prostate Cancer Risk Management Programme (PCRMP) launched in November 2002 provides guidelines for general practitioners (GPs) on age-specific prostate-specific antigen (PSA) cutoff levels in asymptomatic men. The impact of the PCRMP on GP referrals is unknown. This study investigates whether there was a change in the proportion of asymptomatic men with raised PSA levels $\left(\geqslant 3 \mathrm{ng} \mathrm{ml}^{-1}\right.$ ) who were referred to urologists since the launch of the guidelines. Sixty-nine general practices in four areas of England and the main pathology laboratory in each area, which had participated in our previous research, were asked to provide data. Forty-eight practices (70\%) provided retrospective data on urological referrals in men who had a PSA test taken in the periods I December 200I to 3I May 2002 (pre-launch) and I December 2003 to 3I May 2004 (post-launch). Data on referrals were completed for 709 (79\%) out of 898 and 1040 (90\%) out of I I 57 raised records pre- and post-launch, respectively. The percentage of men with raised PSA levels who were asymptomatic was similar in both time periods (19-20\%) and the proportion referred to urologists according to the PCRMP guidelines did not increase significantly over time (24\% pre-launch and $29 \%$ post-launch, $P=0.42$ ). The referral rate was lower than expected if the guidelines had been followed. The influence of the guidelines seems to have been low. At the time of data collection, 56\% (I I 2 out of 200) of GP partners reported that they were aware of receiving the PCRMP pack. To ensure future, effective implementation of guidelines requires evaluation.

British Journal of Cancer (2008) 98, I I76- I I8I. doi:I0.1038/sj.bjc.660429 I www.bjcancer.com

Published online 18 March 2008

(c) 2008 Cancer Research UK

Keywords: primary health care; hospital referral; health education; prostate-specific antigen

The rate of prostate-specific antigen (PSA) testing for prostate cancer has been increasing in the United Kingdom since the early 1990s (Gavin et al, 2004; Melia et al, 2004; NHS Cancer Screening Programmes, 2004). Part of this increase will be due to testing for prostate cancer in asymptomatic men. In 28 areas of England and Wales, using data collected from 1 December 2001 to 31 May 2002, we had estimated the annual rate of PSA testing by general practitioners (GPs) in men aged 45-84 years with no previous diagnosis of prostate cancer to be $6 \%$, with the rate of asymptomatic testing being 2\% (Melia et al, 2004). In September 2002, the NHS Prostate Cancer Risk Management Programme (PCRMP) was launched (NHS Cancer Screening Programmes, 2008). All GPs and urologists in England were sent the PCRMP information pack, which contained materials to help men requesting a PSA test to make an informed choice about the benefits and potential harms of screening. The effect of the programme on knowledge and intention to be tested has been studied (Watson et al, 2006). The programme also provided guidelines on the age-specific PSA cutoff levels for urological referral in asymptomatic men: aged 50-59 years $\geqslant 3 \mathrm{ng} \mathrm{ml}^{-1}, 60-69$ years $\geqslant 4 \mathrm{ng} \mathrm{ml}^{-1}$ and 70 years or more $>5 \mathrm{ng} \mathrm{ml}^{-1}$. The impact of the initiative on referral rates for men with a raised PSA is unknown.

The results presented in this paper compare the rates of urological referral between two 6-month periods before and after

*Correspondence: Dr J Melia; E-mail: jane.melia@icr.ac.uk

Received 7 November 2007; revised I February 2008; accepted 5 February 2008; published online 18 March 2008 the introduction of the PCRMP, specifically in asymptomatic men. A randomised controlled trial could not be conducted because of the nationwide distribution of PCRMP packs. Data from our previous study in England (Melia et al, 2004) provided a baseline for the present study. Additional data on PSA testing were collected from a subset of the pathology laboratories and data on referrals from selected general practices. A full report on the study is available on the NHS Cancer Screening Programmes website.

\section{MATERIALS AND METHODS}

\section{Study areas and selection of general practices}

The pathology laboratory at the main hospital in each of the study areas Chichester, Sutton \& Merton, Truro and York, which had provided timely data in the previous study (Melia et al, 2004), agreed to take part in the study. Data were collected on PSA requests from general practices in our previous study. The criteria for selecting the original group of practices were that they should routinely send all NHS PSA requests to the laboratory at the main hospital in their area, and that all GP partners should provide signed consent.

These practices were invited to participate in the present study. Each GP partner completed a one-page questionnaire on demographic data, membership of the Royal College of General Practitioners (MRCGP) and awareness of receiving the PCRMP pack. 


\section{Data collection on PSA requests and referrals}

Data on PSA requests from the pathology laboratories were collected for the period 1 December 2001 to 31 May 2004. The variables were specimen number, date of test, name and date of birth of man receiving test, NHS number and hospital number, name of GP and practice, and total PSA level $\left(\mathrm{ng} \mathrm{ml}^{-1}\right)$. Patientbased set of records was formed.

It was not feasible to ask the GPs to provide retrospective data on referrals for the full $2 \frac{1}{2}$ year period, so data were collected for one period pre-launch (1 December 2001 to 31 May 2002) and another period post-launch (1 December 2003 to 31 May 2004). The first time period was chosen because data had already been collected on reason for test (Melia et al, 2004). The second time period was chosen at the same time of year to avoid confounding from seasonal variation in rate of testing and to ensure that GPs would have had time to assess and actively use the PCRMP packs distributed in September 2002.

Referral data were collected on all men with a raised PSA value $\left(\geqslant 3 \mathrm{ng} \mathrm{ml}^{-1}\right)$, all men with more than one test over the two time periods and a random $25 \%$ sample of men with a single low PSA value $\left(<3 \mathrm{ng} \mathrm{ml}^{-1}\right)$. Thus, data collection concentrated mostly on records with PSA levels above the minimum PCRMP age-specific level of $3 \mathrm{ng} \mathrm{ml}^{-1}$ to reduce the number of patient records to be searched. A pro forma was prepared for each man, listing his PSA tests (Appendix A). The form included definitions of the reasons for tests as used in the previous study (Melia et al, 2004). There were four categories: men with no previous diagnosis of prostate cancer who were asymptomatic, symptomatic or being re-tested, and men already diagnosed with prostate cancer. Data on urological referrals included the date of referral and hospital name. Reasons for nonreferral or for not being able to complete a pro forma were reported. Each general practice was paid a flat rate per patient record checked.

It was not feasible to ask retrospectively whether the PCRMP pack had been used during patient consultations in the postlaunch period because this was not recorded in patient notes.

A questionnaire on local initiatives was sent to the consultant urologists, chairmen of the Primary Care Trusts and Directors of Public Health. However, no initiatives were identified up to the end of the post-launch study period.

\section{Sample size}

The sample size was selected to give $80 \%$ power to detect, at the $5 \%$ level of significance, a difference of $70 v s 83 \%$ in the proportions referred before and after the distribution of leaflets. Data collection resulted in a larger population being studied than originally planned with a larger number of PSA tests but a lower rate of urological referral (overall $<30 \%$ in both study periods). The larger population resulted in the study being powered to detect changes from 20 to $40 \%$ in the proportion of men referred.

\section{Analysis}

Poisson regression analyses were used to study the relation between GP partners' awareness of receiving the PCRMP pack and GP characteristics, and the distribution of the proportion of GP partners per practice aware of the PCRMP packs has been studied.

Analyses were conducted on the first PSA test recorded for each man in each of the pre- and post-launch periods. The definition of 'first recorded test' is restricted to PSA tests reported within a strict time period and does not refer to the first PSA test ever taken for an individual. The men were aged $45-84$ years at time of their first test, had a PSA test within either of the two time periods pre- and post-launch, and were not reported dead or no longer registered at their study practice.

The analyses of referral rates in this paper are restricted to men who were reported to be asymptomatic at the time of their PSA test in each period. The referral rate was defined as the proportion of asymptomatic men with no previous diagnosis of prostate cancer who were referred to urologists by their GPs following a PSA test. The proportions of men referred were studied within groups of men categorised by the age-specific PSA cutoff levels defined by the PCRMP.

In the analyses of data on men's individual records, it was not possible to study variation in referral rates by practice, or between GPs within practices, because of the small number of men being referred. Social deprivation was not included in the analyses, as individual-based data were not collected on social class or postcode, which could have been linked to a social deprivation index.

\section{RESULTS}

\section{Uptake of practices}

Of 71 practices participating in the previous study (Melia et al, 2004), 2 no longer existed in the post-launch period, so 69 were invited, of which $48(70 \%)$ took part in the present study. The uptake rate was $75 \%$ or more in all areas except Truro, which had an uptake rate of $57 \%$ (Fisher's exact test $P=0.47$ comparing the response rate in Truro with the other areas). The invited practices represented $33 \%$ of those invited to participate in the previous study. The uptake was low because many non-responding practices were ineligible, that is, did not use the laboratory for all their PSA tests.

The total male populations aged $45-84$ years registered at the participating practices were 67162 and 70658 men in the pre- and post-launch periods, respectively. There were a total of $200 \mathrm{GP}$ partners at these practices at the time of data collection. The proportions of practices with $1,2-4,5-6$ and $7-8$ or more GP partners were $10 \%(5), 42 \%(20), 40 \%$ (19) and $8 \%$ (4), respectively.

\section{GP awareness of receiving the PCRMP pack}

Awareness of receiving the PCRMP pack was acknowledged by $56 \%$ ( 112 out of 200$)$ of GP partners at the time of data collection with 24 unaware of the pack and 64 who did not know. The proportion of GP partners per practice who were aware of the PCRMP pack varied independently of size of practice. In the five practices with one partner, only one was aware of the PCRMP pack. In the 43 practices with two or more partners, 28 (65\%) had $\geqslant 50 \%$ of partners aware of the PCRMP pack. Of those with more than one partner, there were $12(28 \%)$ practices where all partners were aware of the pack. In Poisson regression, awareness reported by the GPs did not differ significantly between areas and it was not related to age, gender, MRCGP, number of years working as a GP or number of sessions per week.

\section{Data completeness}

Out of 2494 and 3209 PSA requests in the pre- and post-launch periods, respectively, there were 12 records with missing data on PSA value or patient name, and one record with gender coded female. Record linkage led to 2318 and 3030 men with at least one PSA test in the pre- and post-launch periods, respectively (Table 1). Excluding men reported to be deceased or no longer registered at the practices resulted in pre-launch $515(36.3 \%)$ out of 1420 men with low records and $709(79.0 \%)$ out of 898 men with raised PSA levels available for analysis including those with multiple tests and post-launch $607(32.4 \%)$ out of 1873 and 1040 (89.9\%) out of 1157 , respectively (Table 1). Data requested on the pro forma on ethnic group and family history of prostate cancer could not be analysed, as high proportions of records had missing data ( $>30 \%$ for ethnicity and $86 \%$ for family history). 
Table I Number of men for whom data were collected and counts of exclusions by time period and whether the PSA level was low $\left(<3 \mathrm{ng} \mathrm{ml}^{-1}\right)$ or raised $\left(\geqslant 3 \mathrm{ng} \mathrm{ml}^{-1}\right)$

\begin{tabular}{|c|c|c|c|c|c|c|}
\hline & \multicolumn{3}{|c|}{$\begin{array}{l}\text { Pre-launch, I December } \\
2001 \text { to 3I May } 2002\end{array}$} & \multicolumn{3}{|c|}{$\begin{array}{l}\text { Post-launch, I December } \\
2003 \text { to } 31 \text { May } 2004\end{array}$} \\
\hline & Total & $\begin{array}{l}\text { No. with Ist test } \\
\text { low record }\end{array}$ & $\begin{array}{l}\text { No. with Ist test } \\
\text { raised record }\end{array}$ & Total & $\begin{array}{l}\text { No. with Ist test } \\
\text { low record }\end{array}$ & $\begin{array}{l}\text { No. with Ist test } \\
\text { raised record }\end{array}$ \\
\hline No. of men aged $45-84$ years before stratified sampling & 2318 & 1420 & 898 & 3030 & 1873 & 1157 \\
\hline \multicolumn{7}{|l|}{ Reasons for exclusions from laboratory data files } \\
\hline $\begin{array}{l}\text { At one lab, GPs only notified of rounded values, } \\
\text { so some PSA levels were classified as low }\end{array}$ & & NA & 20 & & NA & 0 \\
\hline No. of men aged $45-84$ years after stratified sampling & 1418 & 563 & 855 & 1788 & 663 & 1125 \\
\hline \multicolumn{7}{|c|}{ Reasons for exclusion from data analysis after data collection from general practices } \\
\hline $\begin{array}{l}\text { Men's records not available due to death or no longer } \\
\text { registered at practice }\end{array}$ & 194 & 48 & 146 & $|4|$ & 56 & 85 \\
\hline
\end{tabular}

GP, general practitioner; PSA, prostate-specific antigen.

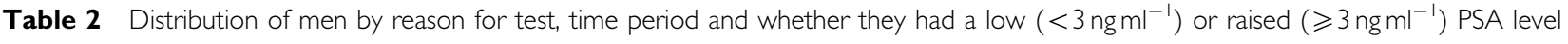

\begin{tabular}{|c|c|c|c|c|c|c|c|c|}
\hline \multirow[b]{3}{*}{ Reason for test } & \multicolumn{4}{|c|}{$\begin{array}{l}\text { Pre-launch, I December } \\
2001 \text { to 3I May } 2002\end{array}$} & \multicolumn{4}{|c|}{$\begin{array}{l}\text { Post-launch, I December } \\
2003 \text { to 3I May } 2004\end{array}$} \\
\hline & \multicolumn{2}{|c|}{ Low records $\mathbf{s}^{\mathrm{a}}$} & \multicolumn{2}{|c|}{ Raised records } & \multicolumn{2}{|c|}{ Low records ${ }^{a}$} & \multicolumn{2}{|c|}{ Raised records } \\
\hline & No. & $\%$ & No. & $\%$ & No. & $\%$ & No. & $\%$ \\
\hline Asymptomatic & 194 & 37.7 & $|3|$ & 18.5 & 234 & 38.6 & 203 & 19.5 \\
\hline Symptomatic & 188 & 36.4 & 284 & 40.1 & 201 & 33.1 & 445 & 42.8 \\
\hline Not known & 5 & 1.0 & 6 & 0.8 & 16 & 26.4 & 16 & 1.5 \\
\hline Total included in data collection & \multirow{2}{*}{\multicolumn{4}{|c|}{$\chi_{4}^{2}=100.3, P<0.001$}} & 607 & 100 & 1040 & 100 \\
\hline $\begin{array}{l}\text { Significance of difference in distribution of } \\
\text { reason for test between low and raised records }\end{array}$ & & & & & \multicolumn{4}{|c|}{$\chi_{4}^{2}=|32.9, P<0.00|$} \\
\hline
\end{tabular}

PSA, prostate-specific antigen. No significant differences between the two time periods were found in the distribution of reason for test among men with low or men with raised PSA levels. ${ }^{a}$ Based on sub-sample, see Table I.

\section{Reason for test}

The percentage distributions of reason for test were similar in both time periods (Table 2). A higher proportion of men with low PSA levels were asymptomatic compared with men with raised PSA levels (pre-launch: 38 and 19\%, respectively, $\chi_{1}^{2}=56.3, P<0.001$; post-launch: 39 and $20 \%$, respectively, $\chi_{1}^{2}=71.2, P<0.001$ ).

\section{Urological referrals in asymptomatic men}

The proportions of asymptomatic men referred among those with raised PSA levels did not increase significantly from the pre- to post-launch period (13.7 and $18.2 \%$, respectively, Table 3 ). There were no referrals in asymptomatic men with low PSA levels. There was also no significant difference in the referral rates by area (Fisher's exact test $P=0.33$ ). Among those not referred, the most frequent reason was PSA too low $(87 \%, 347$ out of 400 , postlaunch), and re-testing scheduled by GP in general practice (7\%, 29 out of 400, post-launch, Table 3). In the raised PSA group, additional reasons for non-referral included serious comorbidity.

Analysis of referral according to the PCRMP age-specific cutoff levels, restricted to men aged 50-84 years, showed that in the prelaunch period no men were referred with PSA levels below the PCRMP cutoff levels, and there was no significant increase in the proportion of men referred over time in this group $(0.0-1.6 \%$, Fisher's exact test $P=0.07)$. There was also no significant increase in the proportion of men referred among those with PSA levels above the cutoff levels $(24.0-29.4 \%, P=0.42$, Table 4$)$. No men were referred in the age group 45-49 years below the age range defined by the PCRMP (Table 4). There was also no significant increase in the proportion referred with age (Fisher's exact test $P>0.20$ ).

Of all 55 men referred, $45(82 \%)$ were referred within 2 months of their test. In pre-launch findings, the median PSA value associated with referral increased with age from $5.2 \mathrm{ng} \mathrm{ml}^{-1}$ in 50 - to 59 -year olds to $6.8 \mathrm{ng} \mathrm{ml}^{-1}$ in 70 - to 84 -year olds. Post-launch findings were similar with the median PSA value associated with referral increasing from $6.2 \mathrm{ng} \mathrm{ml}^{-1}$ in 50 - to 59 -year olds to $13.0 \mathrm{ng} \mathrm{ml}^{-1}$ in 70 - to 84 year olds. Five men post-launch with PSA levels below the PCRMP age-specific cutoffs were referred: in these men, PSA levels ranged from 3 to $4.9 \mathrm{ng} \mathrm{ml}^{-1}$ in the age range $60-84$ years).

Among asymptomatic men not referred post-launch but having a PSA level that was above the PCRMP age-specific guidelines, 18 aged $50-59$ years had levels ranging from 3 to $8.5 \mathrm{ng} \mathrm{ml}^{-1}, 29$ aged $60-69$ years had levels ranging from 4 to $9.5 \mathrm{ng} \mathrm{ml}^{-1}$ and 30 aged $70-84$ years had levels ranging from 5.1 to $23.6 \mathrm{ng} \mathrm{ml}^{-1}$. When these data were restricted further to those non-referrals for which the GPs reported the PSA level to be too low for referral, the ranges were $3-5.2,4-8.9$ and $5.3-7.5 \mathrm{ng} \mathrm{ml}^{-1}$, respectively. 
Table 3 Number of urological referral and reasons for non-referral in asymptomatic men by time period and whether they had a low $\left(<3 \mathrm{ng} \mathrm{ml}^{-1}\right)$ or raised $\left(\geqslant 3 \mathrm{ng} \mathrm{ml}^{-1}\right)$ PSA level

Distribution of non-referrals by reason

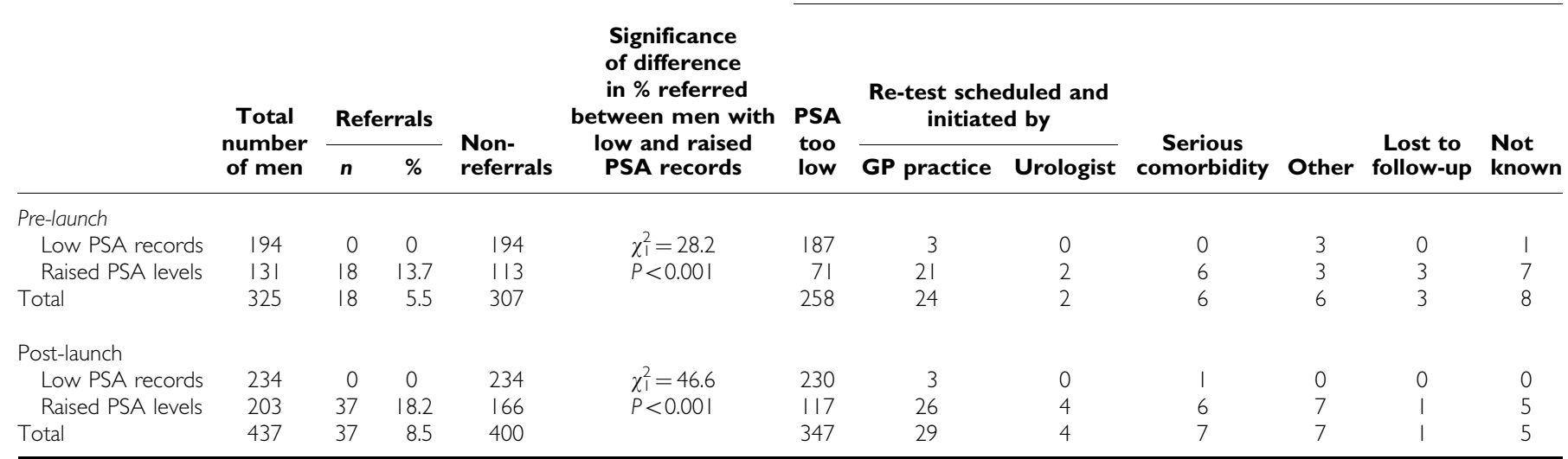

GP, general practitioner; PSA, prostate-specific antigen. Significance: no significant differences between the two time periods in distributions of referral and non-referral for either low or raised PSA levels.

Table 4 Proportion of asymptomatic men referred pre- and post-launch aged 45-84 years grouped by PSA level and age

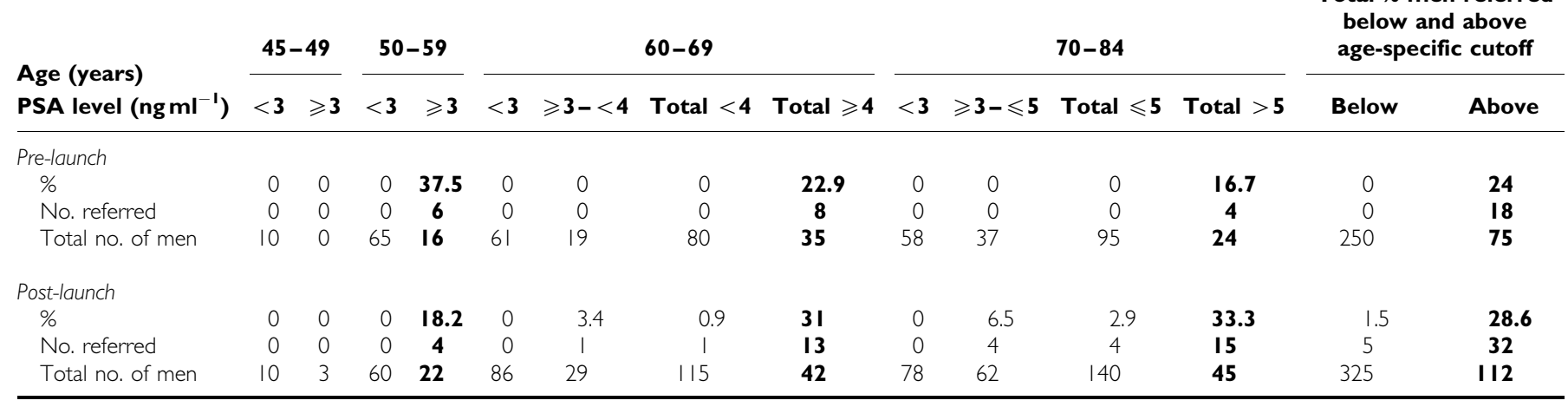

PCRMP, Prostate Cancer Risk Management Programme; PSA, prostate-specific antigen. Results in bold relate to PCRMP guidelines for referral: aged $50-59$ years $\geqslant 3$ ng $m l^{-1}$, aged 60-69 years $\geqslant 4 \mathrm{ng} \mathrm{ml}^{-1}$ and 70 years or more $>5 \mathrm{ng} \mathrm{ml}^{-1}$. No significant difference in the proportion of referrals between pre- and post-launch periods.

\section{DISCUSSION}

The aim of this study was to investigate the impact of the PCRMP guidelines for age-specific cutoff levels for PSA levels in asymptomatic men on urological referrals. No significant change in the proportion of asymptomatic men being referred to urologists following a PSA test was observed between the two time periods before and after the launch of the PCRMP. The proportions referred were lower than that anticipated. Thus, the influence of the PCRMP guidelines seems to have been low. The relation of the PCRMP guidelines to decisions about referral could not be studied retrospectively because these data are not routinely recorded. However, at the time of data collection, $56 \%$ of GP partners in the study reported being aware that they had received the PCRMP packs, and the proportion of GP partners aware per practice showed a wide variation from 0 to $100 \%$.

GPs adopted a varied but cautious approach to referral, with all non-referral considered by their GP to have a low PSA level having levels below $10 \mathrm{ng} \mathrm{ml}^{-1}$. It is not know why some GPs chose to take a PSA test when the patient had comorbidities, which influenced the decision not to refer them. It was not feasible to collect this information, as the GP consulting at the time of the PSA test was not necessarily the one providing the retrospective data. No local guidelines for referral of asymptomatic men were reported. Review of the guidance provided in the study laboratories' pathology reports was primarily concerned with symptomatic men and those already diagnosed with prostate cancer. Re-testing was the most frequent management in non-referrals in men with raised PSA levels.

The main limitations of the study concern the choice of study design, the uptake of the practices, the completeness of data collection and variation in laboratory assays to measure PSA. It was not possible to conduct a randomised controlled trial because the programme was launched nationwide. The observational design used may have been affected by local and national influences. However, if the PCRMP guidelines had had a strong impact on PSA testing and referrals, this should have been detected.

The data collected on GP partners' awareness of the PCRMP packs are limited because knowledge and views on the guidelines were not studied in detail. As these data were only available at the time of data collection, it was not appropriate to link them to the retrospective referral data: awareness among GP partners does not imply that the PCRMP packs were used during consultations, and the GPs helping with data collection from patient notes were not always those who had made the referral decisions. It was also not possible to study men's experiences of PSA testing as has been done in one study (Evans et al, 2007).

Data collection on referrals was restricted to two identical times of year in 2001/2002 and 2003/2004. This controlled for time of 
year, and the second period allowed GPs a year after the launch to take on board the PCRMP guidelines. It was not feasible to ask GPs to provide data for a longer time period.

The practices were chosen from our previous study to enable the use of data already collected. The practices in the previous study were not a random sample, representing just more than $30 \%$ of those recorded as using the pathology laboratories. The practices in the study of referral rates represent a smaller proportion of single-handed practices (10\%) than nationally (27\% in 2004) (Department of Health, $2005)$. They also represented a narrow range of social deprivation scores linked to practice postcodes: the mean $( \pm$ s.d.) Townsend scores for the participating practices were $-2.62 \pm 0.08,-1.46 \pm 0.99$, $-1.32 \pm 0.50$ and $-2.16 \pm 0.83$ in Chichester, Sutton \& Merton, Truro and York, respectively. It is possible that the participating GPs were more likely to test for PSA than GPs in more deprived areas, but it is unclear what effect the selection bias could have had on urological referrals and use of the PCRMP guidelines.

Data on referral were incomplete for men who had died or who were no longer registered at the practices, as their notes were not available. The proportions were higher pre-launch than post-launch $(13.7 \%, 194$ out of 1418 , and $7.9 \%, 141$ out of 1788 , respectively, $\left.\chi_{1}^{2}=28.4, P=0.0001\right)$. Men with missing data were older and had higher levels of PSA compared with men not missing these data. Thus, those excluded from the analyses were more likely to have been symptomatic or diagnosed with prostate cancer than men for whom data were completed. The results for referral rates in asymptomatic men are less likely to have been affected by these biases than in men tested for other reasons.

All of the laboratories participated in the Quality Assurance scheme for PSA measurement (Milford Ward et al, 2001). Their methods of measurement were Bayer Immunol, Bayer Centaur and DPC Immunite (two laboratories). Variation in bias of PSA measurements by these assays (Roddam et al, 2006) is likely to have affected a very small proportion of men, as the GPs were not using the same cutoff levels. The reliability of the referral data was strengthened by asking for a date of referral and consultant name. Analysis of reason for test by PSA level showed that low levels were associated with asymptomatic testing, as has been found in screening trials (De Koning et al, 2002). The distribution of reason for test in men with low and raised PSA levels was also as expected in both time periods of the study (Table 2).

Few studies have reported on urological referral rates in general practice linked to specific PSA tests, partly because there is considerable workload involved in retrospectively searching patient notes. In the United States (Dyche et al, 2006), referral rates were studied from 1998 to 2004 in men aged $\geqslant 75$ years with no previous prostate cancer diagnosis attending one centre in Iowa: in those with PSA levels between 0.1 and $4.0 \mathrm{ng} \mathrm{ml}^{-1}, 28.6 \%$ were referred, and in those with PSA levels $>4.0 \mathrm{ng} \mathrm{ml}^{-1}, 52 \%$ were referred. For the comparable populations defined by age and PSA level in our study, 7\% (8 out of 120) and 30\% (56 out of 186) were referred, respectively, pre-launch, representing the period $2001 / 2002$.

As the rate of PSA testing continues to increase in England, and there is no standard management of tests in asymptomatic men, evaluation of the PCRMP guidelines is essential (Watson et al, 2006). Without routine, standardised data on reasons for PSA tests in general practice, it will be impractical to monitor trends in use of the PSA test, and its impact on GP workload and detection of prostate cancer. There is an urgent need for evaluation to ensure future, effective implementation of guidelines.

\section{Approval}

The study was approved by NHS Research Ethics Service (04/ MRE01/39) and by the Patient Information Advisory Group (PIAG 2-06(f)/2004).

\section{ACKNOWLEDGEMENTS}

This work was funded by the Policy Research Programme of the Department of Health. The views are those of the authors and not necessarily those of the Department of Health. We are grateful to Dr J Quiney, Dr Christine Chowne and Mr Malcolm Redman at St Richard's Hospital Chichester; Dr Jeff Barron and Mr Steve Bunnage at St Helier Hospital Sutton; Dr Simon Fleming and Mr Barry Thomas at Royal Cornwall Hospital Truro; and Dr Margaret Sinclair at York District Hospital. We thank staff at all the GP practices for their assistance with data collection, and Dr Alison Shepherd for specific advice on the study protocol. We acknowledge the use of the National Primary Care Database managed at the National Primary Care Research and Development Centre. The Database was devised by Professor Deborah Baker and constructed by Justin Hayes at the Regional Research Laboratory, School of Geography, University of Manchester (Director: Dr Robert Barr); SEE IT consultancy designed and built the map interface. The database is currently maintained by Evangelos Kontopantelis and Sylvia Wright at NPCRDC. The data file on number of men registered at each practice was supplied by $\mathrm{Mr}$ Andrew Wagner from General Medical Services Statistics, National PCT Database, National Primary Care Research and Development Centre, University of Manchester.

\section{REFERENCES}

De Koning HJ, Auvinen A, Berenguer Sanchez A, Calais da Silva F, Ciatto S, Denis L, Gohagan JK, Hakama M, Hugosson J, Kranse R, Nelen V, Prorok PC, Schroder FH, ERSPC Trial (2002) Large-scale randomized prostate cancer screening trials: program performances in the European randomized screening for prostate cancer trial and the prostate, lung, colorectal and ovary cancer trial. Int J Cancer 97: 237-244

Department of Health (2005) Statistics for General Medical Practitioners in England: 1994-2004 (bulletin 2005/02). DH Publications: London

Dyche DJ, Ness J, West M, Allareddy V, Konety BR (2006) Prevalence of prostate specific antigen testing for prostate cancer in elderly men. J Urol 175: $2078-2082$

Evans R, Edwards AGK, Elwyn G, Watson E, Grol R, Brett J, Austoker J (2007) 'It's a maybe test': men's experiences of prostate specific antigen testing in primary care. Br J Gen Pract 57: 303-310

Gavin A, McCarron P, Middleton RJ, Savage G, Catney D, O’Reilly D, Keane PF, Murray LJ (2004) Evidence of prostate cancer screening in a UK region. BJU Int 93: $730-734$

Melia J, Moss S, John L, and Contributors in the participating laboratories (2004) Rate of prostate specific antigen testing in general practice in
England and Wales in asymptomatic and symptomatic patients: a crosssectional study. BJU Int 94: $51-56$

Milford Ward A, Catto J, Hamdy FC (2001) Prostate specific antigen: biology, biochemistry and available commercial assays. Ann Clin Biochem 38: $633-651$

NHS Cancer Screening Programmes (2004) NHS prostate cancer risk management: second survey of prostate specific antigen services in England. http://www.cancerscreening.nhs.uk/prostate/psa-tests.html\#england

NHS Cancer Screening Programmes (2008) Prostate cancer risk management. http://www.cancerscreening.nhs.uk/prostate/index.html

Roddam AW, Rimmer J, Nickerson C, Ward AM (2006) Prostate-specific antigen: bias and molarity of commercial assays for PSA in use in England. Ann Clin Biochem 43: 35-48

Watson E, Hewitson P, Brett J, Bukach C, Evans R, Edwards A, Elwyn G, Cargill A, Austoker J (2006) Informed decision making and prostate specific antigen (PSA) testing for prostate cancer: a randomised controlled trial exploring the impact of a brief patient decision aid on men's knowledge, attitudes and intention to be tested. Patient Educ Couns 63: $367-379$ 


\section{Appendix A}

\section{PSA Referral Study: Code Sheet Instructions}

\section{Code for Reason for Test}

\begin{tabular}{|c|c|}
\hline Asym & $\begin{array}{l}\text { ASYMPTOMATIC MEN WITH NO PRECEDING DIAGNOSIS OF PROSTATE CANCER } \\
\text { Men who request screening, but not those who have attended because of prostate symptoms } \\
\text { Men offered PSA screening or re-screening as part of general health check eg Well Man Clinic } \\
\text { Opportunistic test by GP while patient attended for health reasons unrelated to prostate cancer } \\
\text { (use of these categories should be independent of any findings from rectal examination) }\end{array}$ \\
\hline Sym & $\begin{array}{l}\text { SYMPTOMATIC MEN WITH NO PRECEDING DIAGNOSIS OF PROSTATE CANCER } \\
\text { Men attending because of concerns about prostate symptoms }\end{array}$ \\
\hline $\mathrm{PrCa}$ & $\begin{array}{l}\text { MEN WITH PRECEDING DEFINITIVE DIAGNOSIS OF PROSTATE CANCER } \\
\text { Men undergoing regular PSA measurement as a marker of disease activity }\end{array}$ \\
\hline NK & Not known \\
\hline
\end{tabular}

\section{Code for Reason for No Referral}

I - PSA too low (no known Prostate Cancer diagnosis)

2 - Patient diagnosed with prostate cancer prior to this test

3 - Patient has other serious co-morbidity including senility/old age

$\mathbf{4 a}$ - Re-test was scheduled, no previous referral (no known Prostate Cancer diagnosis)

$\mathbf{4 b}$ - Re-test was scheduled, previous referral (no known Prostate Cancer diagnosis)

5 - Other

$\mathbf{6}$ - Lost to follow up

NK - Not known

\section{Example of a Patient Proforma}

PSA Referral Study: GP Patient Proforma

Patient Name:
GP Practice Name:

Sex:
Practice ID:

Name of GP:

PLEASE COMPLETE by circling answers and completing the table. Please indicate if any corrections are needed to pre-coded data eg. Reason for Test

African or African

NO YES

NOT KNOWN

Family history of NO

YES

NOT KNOWN

Caribbean origin:

prostate cancer:

\section{Date of PSA Test}

Total PSA
Result

(ng/ml)
Reason

for Test

(see code sheet)
NO urological referral

following test: Reason

(see code sheet)
YES - urological

referral

following test

Date
Hospital Consultant NHS/

Private

If reason for NO urological referral is 'Other' please describe

If patient has been diagnosed with prostate cancer please give date of diagnosis ...... / ...............

IF UNABLE TO COMPLETE FORM (please circle)

Patient has: Moved Died Other 'Other' give reason...

THANK YOU

Please return to the Cancer Screening Evaluation Unit, Institute of Cancer Research, SM2 5NG. 